\title{
Early magnesium treatment after aneurysmal subarachnoid hemorrhage: an individual patient data meta-analysis
}

\author{
WM van den Bergh", writing groups of MASH-I, IMASH, MASH-II, MASH and FAST-MAG \\ From ESICM LIVES 2015 \\ Berlin, Germany. 3-7 October 2015
}

\section{Introduction}

Delayed cerebral ischemia (DCI) is an important cause of poor outcome after aneurysmal subarachnoid hemorrhage $(\mathrm{SAH})$. Trials on magnesium treatment starting < 4 days after symptom onset found no effect on poor outcome or DCI in SAH. Earlier instalment of treatment might be more effective, but individual trials had not enough power for such a sub-analysis.

\section{Objectives}

We performed an individual patient data meta-analysis to study whether magnesium is effective when given within different time frames within 24 hours after the SAH.

\section{Methods}

Patients were divided into categories according to the delay between symptom onset and start of the study medication: < 6 hours, 6-12 hours, 12-24 hours, > 24 hours. We calculated adjusted risk ratios (aRR) with corresponding 95\% confidence intervals (CI) for magnesium versus placebo treatment for poor outcome and DCI.

\section{Results}

We included 5 trials totalling 1981 patients, 83 patients started treatment $<6$ hours. For poor outcome the aRRs of magnesium treatment for start $<6$ hours were 1.44 (95\%CI:0.83-2.51); for 6-12 hours 1.03(0.65-1.63), for 12-24 hours 0.84(0.65-1.09) and for $>24$ hours 1.06 (0.87-1.31), and for DCI, $<6$ hours 1.76(0.68-4.58), for
6-12 hours 2.09(0.99-4.39), for 12-24 hours 0.80(0.56$1.16)$ and for $>24$ hours $1.08(0.88-1.32)$.

\section{Conclusions}

This meta-analysis suggests no beneficial effect of magnesium treatment on poor outcome or DCI when started early after SAH onset. Although the number of patients was small and a beneficial effect cannot be definitively excluded, we found no justification for a new trial with early magnesium treatment after SAH.

Published: 1 October 2015

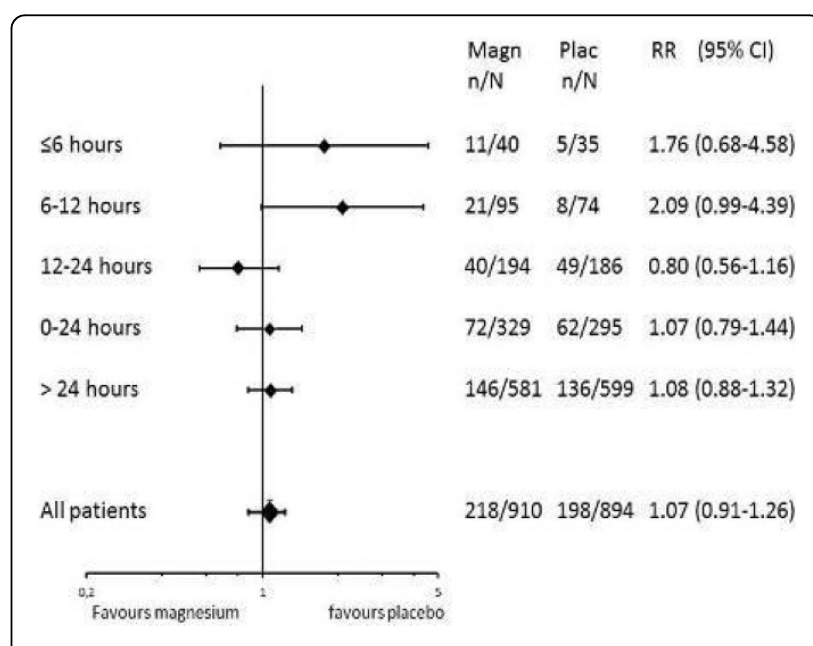

Figure 1 Adjusted RR for occurrence of DCl for magnesium ve. 


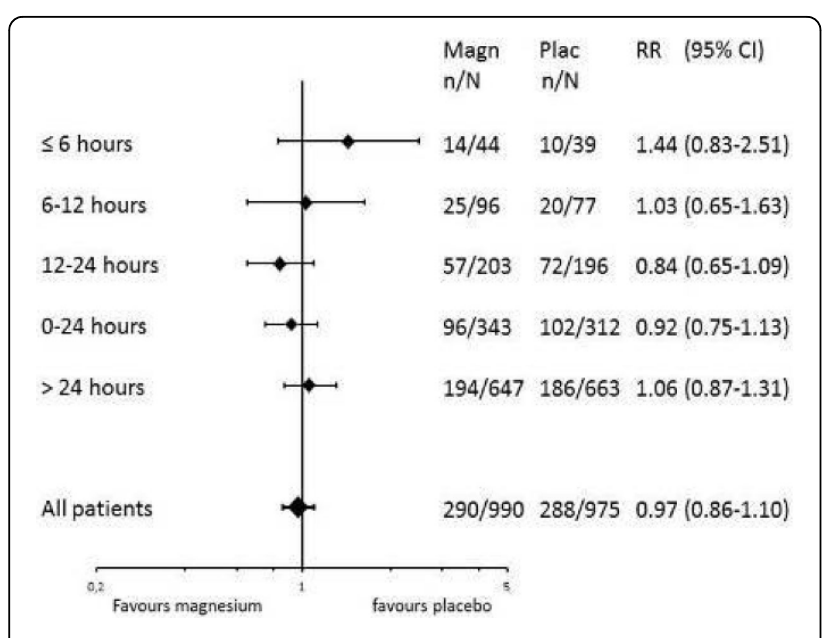

Figure 2 Adjusted RR for poor outcome for magnesium versus.

doi:10.1186/2197-425X-3-S1-A774

Cite this article as: van den Bergh and : Early magnesium treatment after aneurysmal subarachnoid hemorrhage: an individual patient data meta-analysis. Intensive Care Medicine Experimental 2015 3(Suppl 1):A774.

\section{Submit your manuscript to a SpringerOpen ${ }^{\mathcal{D}}$ journal and benefit from:}

- Convenient online submission

- Rigorous peer review

- Immediate publication on acceptance

- Open access: articles freely available online

- High visibility within the field

- Retaining the copyright to your article 